\title{
Regulatory Framework for Conducting Clinical Research in Canada
}

\author{
Josmar K. Alas, Glenys Godlovitch, Connie M. Mohan, Shelly A. Jelinski, \\ Aneal A. Khan
}

\begin{abstract}
Research in human subjects is at the core of achieving improvements in health outcomes. For clinical trials, in addition to the peer review of the results before publication, it is equally important to consider whether the trial will be conducted in a manner that generates data of the highest quality and provides a measure of safety for the participating subjects. In Canada, there is no definitive legislation that governs the conduct of research involving human subjects, but a network of regulations at different levels does provide a framework for both principal investigators and sponsors. In this paper, we provide an overview of the federal, provincial and institutional legislation, guidelines and policies that will inform readers about the requirements for clinical trial research. This includes a review of the role of the Food and Drug Regulations under the Food and Drugs Act and the Tri-Council Policy Statement (TCPS2), an overview of provincial legislation across the country, and a focus on selected policies from institutional research ethics boards and public health agencies. Many researchers may find navigation through regulations frustrating, and there is a paucity of information that explains the interrelationship between the different regulatory agencies in Canada. Better understanding the process, we feel, will facilitate investigators interested in clinical trials and also enhance the long-term health of Canadians.
\end{abstract}

RÉSUMÉ: Cadre réglementaire de la recherche clinique au Canada. La recherche chez les sujets humains est essentielle au progrès dans le domaine de la santé. En ce qui concerne les essais cliniques, outre l'examen par des pairs avant la publication des résultats, il est également important de considérer si l'essai clinique sera mené de telle sorte qu'il puisse générer des données de la plus haute qualité et d'assurer la sécurité des sujets qui y participeront. Au Canada, il n'existe pas de cadre législatif précis gouvernant la conduite responsable de la recherche chez des sujets humains. Cependant, un ensemble de règlements à différents niveaux fournit un cadre tant aux chercheurs principaux qu'aux commanditaires de la recherche. Dans cet article, nous offrons un aperçu de la législation fédérale, provinciale et institutionnelle, des lignes directrices et des règles qui renseigneront les lecteurs sur les exigences à respecter dans la conduite de la recherche clinique. Nous incluons une revue du rôle du Règlement sur les aliments et drogues établi sous la Loi sur les aliments et drogues et de l'Énoncé de politique des trois Conseils (EPTC 2), un aperçu de la législation provinciale à travers le pays et nous mettons l'accent sur certaines politiques de comités institutionnels d'éthique de la recherche et d'agences de santé publique. Plusieurs chercheurs pourraient éprouver de la frustration à naviguer entre les différentes règlementations et il existe peu d'information qui explique l'interrelation entre les différentes agences de réglementation au Canada. À notre avis, une meilleure compréhension du processus facilitera la tâche des chercheurs intéressés à mener des essais cliniques et améliorera la santé des Canadiens à long terme.

Keywords: Human subjects, clinical trials, clinical research, ethics boards, ethics oversight, regulatory framework, ethics harmonization, regulations

doi:10.1017/cjn.2016.458

Can J Neurol Sci. 2017; 44: 469-474

\section{INTRODUCTION}

The history of clinical research is filled with decisive moments in the development of ethical standards for conducting clinical research on human subjects. For example, in a recent clinical trial in France, one person died and five others were hospitalized. ${ }^{1}$ An official investigation into the incident by France's social affairs inspectorate found no breach in legislation, though both the pharmaceutical company and the contract research organization (CRO) were alleged to be at fault: the pharmaceutical company for not informing authorities about the incident until four days later and the CRO for implementing a faulty protocol and not properly informing subjects about their risks in the trial when they knew that previous participants had complications. ${ }^{2}$ In order to protect the public, many countries have policies and legislation in place guiding principal investigators (PIs) in the ethical conduct of research involving human subjects.

In Canada, the clinical research regulatory framework is constituted by a sum of local, provincial and federal legislation, guidelines and policies. First, PIs are bound to follow the local policies of those research and academic institutions they are affiliated with as well as the policies and requirements of their sponsors and funding entities. Also, provincial legislation dictates the procedures they must follow to obtain approval from a

From the Department of Medical Genetics, Alberta Children's Hospital Research Institute, Cumming School of Medicine, University of Calgary, Calgary, Alberta, Canada (JKA); Department of Community Health Sciences, University of Calgary, Calgary, Alberta, Canada (GG); Department of Medical Genetics, Alberta Children's Hospital Research Institute, Cumming School of Medicine, University of Calgary, Calgary, Alberta, Canada (CMM); Department of Medical Genetics, Alberta Children's Hospital Research Institute, Cumming School of Medicine, University of Calgary, Calgary, Alberta, Canada (SAJ); Department of Medical Genetics and Paediatrics, Alberta Children's Hospital Research Institute, Cumming School of Medicine, University of Calgary, Calgary, Alberta, Canada (AAK).

Received SePtember 23, 2016. Date of Acceptance December 19, 2016. Correspondence to: Josmar K. Alas, Department of Medical Genetics, Alberta Children's Hospital Research Institute, Cumming Schoool of Medicine, University of Calgary, 2500 University Drive NW, Calgary, Alberta, Canada T2N 1N4, Calgary, Alberta, Canada. Email: josmar.alas@ucalgary.ca. 
research ethics board (REB). The federal government also has enacted legislation governing the conduct of clinical trials. Additionally, a set of guidelines for ethical conduct of research have been widely adopted by the research community. Altogether, such a framework leads to multiple steps to be followed before a PI can begin a clinical research project.

This article intends to deliver a summary of the current federal and provincial legislation, guidelines and policies in place for conducting clinical research in Canada, as well as to revisit the level of provincial harmonisation in research ethics reviews, with the objective of outlining the regulatory framework that must be followed by PIs wishing to conduct clinical trial research.

\section{Overview of Legislation, Guidelines and Policies}

In terms of legislation, at the federal level, the only document regulating clinical research in Canada is the Food and Drug Regulations (FDR) under the Food and Drugs Act (Canada). ${ }^{3}$ Application for a clinical trial using a new drug (Phase I, II or III drug trials) or device to Health Canada is referred to as a clinical trial application (CTA) or an Investigational Testing Authorization (ITA), respectively. The CTA is typically filed by the drug manufacturer (sponsor) or the investigator as a sponsorinvestigator. Health Canada will review the application for deficiencies within 30 days, and if the application is accepted, a no objection letter (NOL) is issued. The FDR requires both approval from Health Canada and ethics approval from the local REB before the trial can be initiated. The overall conduct of the trial is ultimately the responsibility of the sponsor, and the local PI must ensure that the trial is conducted in accordance with the protocol and that all regulations are followed.

When it comes to guidelines and policies in Canada, two of them have been adopted on a national scale: one is an international document and the other Canadian. They are, respectively, the International Council for Harmonisation of Technical Requirements for Pharmaceuticals for Human Use-Guidance for Good Clinical Practice (ICH E6), and the Tri-Council Policy Statement: Ethical Conduct for Research Involving Humans (TCPS2 (2014)). The Canadian document, the TCPS2 (2014), as discussed in more detail below, imposes ethics review compliance requirements on institutions that receive public funding from any of the three national funding agencies. The ethics requirements apply to all research involving human subjects, biobanks or genetic material, not just those projects funded by the agencies. Moreover, PIs must abide by provincial and territorial legislation governing the access, disclosure, use and manipulation of personal health information.

The FDR (Part C, Division 5) governs the use of drugs for clinical trials involving human subjects and outlines the steps to obtain approval to sell or import a drug for such use. It also incorporates the sponsor's obligations in conducting research, including good clinical practice (GCP). ${ }^{4}$ In addition, the FDR is the only federal healthcare legislation defining a research ethics board, while also stating their mandate and stipulating their membership requirements. ${ }^{4}$ Canada lacks uniform federal research ethics legislation, unlike some other countries that already have laws in place that regulate REB operations. For instance, the United States Code of Federal Regulations, Title 45, Part 46 (45 CFR 46), is a comprehensive legal framework that defines the rules REBs must abide by when conducting ethics reviews, among other regulations. ${ }^{5}$ Furthermore, the European Union (EU) Clinical Trials Directive
2001/20/EC laid the groundwork for the creation of legislation and policies in each of its member states. ${ }^{6}$

Compliance with the U.S. requirements is effectively imported by reference for U.S.-based research funded, in part or in whole, by the Department of Health and Human Sciences agency when any of it is conducted in Canada. Canadian institutions undertaking the research must have recourse to a registered REB and must have Federalwide Assurance (FWA) registration. Those two elements expressly require confirmation that the REB complies with 45 CFR 46. Canadian REBs and their respective institutions generally are registered and have FWA certificates. Likewise, Canadian PIs conducting research with European sponsors must comply with the European Medicines Agency (EMA)-relevant clinical research requirements, including legislation from the member state where the research is based.

Although Canada was invited to the EU as a non-voting member only, Health Canada (HC) implemented the ICH E6 guidelines in 1997 by publishing the ICH Guidance E6: Good Clinical Practice: Consolidated Guideline. ${ }^{7}$ The ICH E6 was finalised in 1996 by the International Council for Harmonisation (ICH), composed of regulatory agencies and industry associations of Europe, Japan and the United States. It was conceived as an international ethical and scientific quality standard for GCP when undertaking clinical trials involving humans. ${ }^{8}$ This document outlines the roles and duties of the parties involved-REBs, PIs and sponsors-and encompasses REB responsibilities, composition, functions, operations, procedures and records. ${ }^{8}$

The TCPS2 (2014) is a joint policy statement-a living electronic document-devised by the three Canadian federal research agencies: the Canadian Institutes of Health Research (CIHR), the Natural Sciences and Engineering Research Council of Canada (NSERC) and the Social Sciences and Humanities Research Council of Canada (SSHRC) (Figure 1). The TCPS2 (2014) mandate is "to promote the ethical conduct of research involving humans" [TCPS2, Introduction]. ${ }^{9}$ One chapter is devoted to the governance of REBs, including their establishment, procedures and appeals. ${ }^{9}$ Despite each agency having at the time its own ethics guidelines, in 1994 the three council presidents established the Tri-Council Working Group (TCWG), with members from various disciplines (ranging from medicine, law and the social sciences), and whose mandate was "to develop new policies and regulations to replace the Council's existing guidelines for research involving humans." ${ }^{10}$ The creation of this document was regarded as a kind of self-regulation by the research community by taking into account the interests of the general public. ${ }^{10}$ It has been suggested that four factors led to the creation of a consolidated policy. First, there are such contextual factors as a growing research and development sector, new areas of research and the emerging interdisciplinary nature of research; second, the notable evolving nature of ethics around human subjects research; third, the development of international policies, such as the Common Rule in the United States; and fourth, domestic factors, such as universities developing their own human research protection policies, which posed difficulties for multi-centre research. ${ }^{10}$ After submission of the final draft of the document to the agency presidents, the agencies adopted the first edition of the TCPS in 1998, submitting human research funded by the CIHR, NSERC or SSHRC to such policies. The TCPS was interdisciplinary in nature, indicative of the different areas or research of the three agencies. ${ }^{11}$ Currently, the TCPS2 (2014) has 


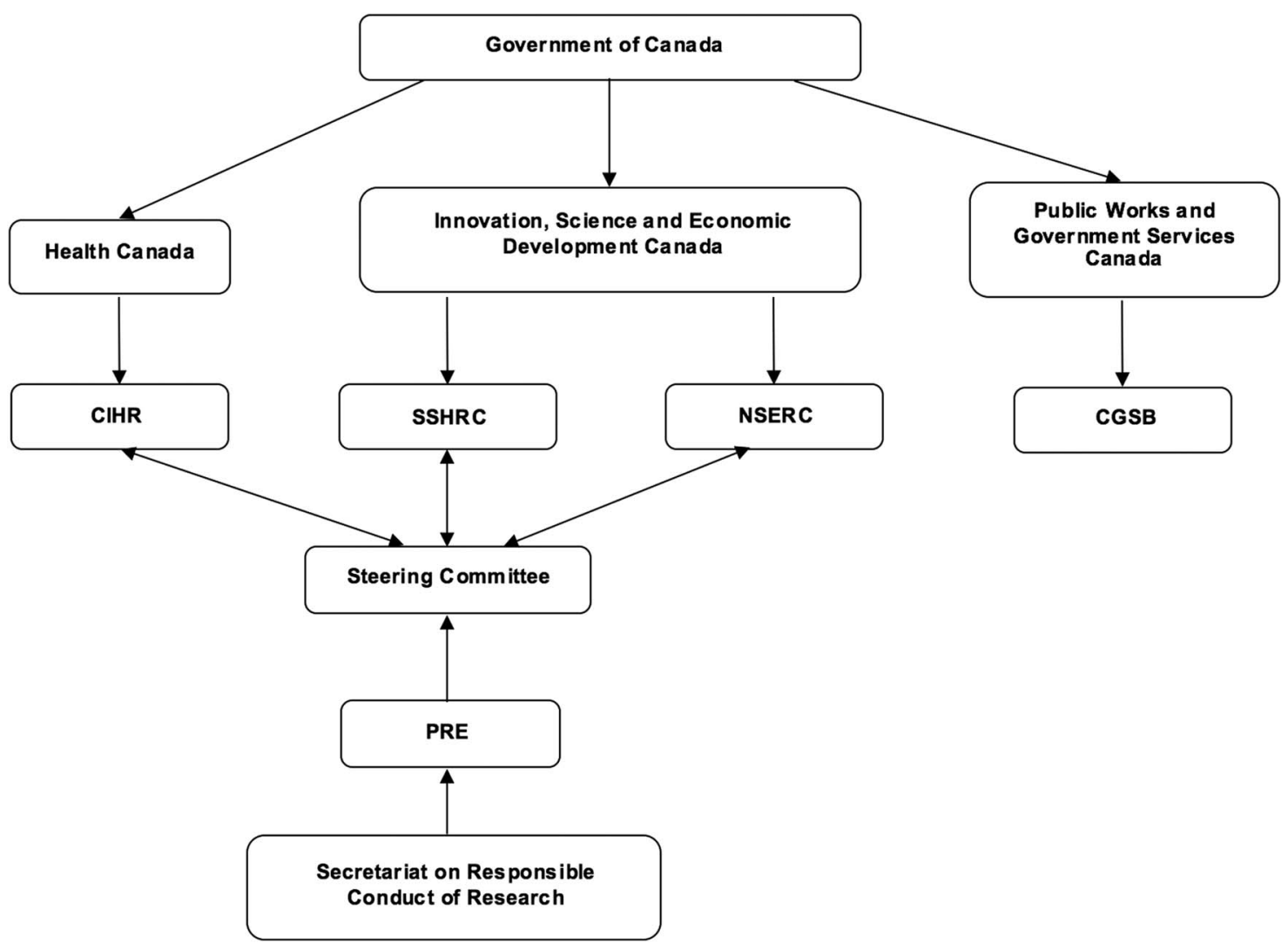

Figure 1: Organizational chart of the three Canadian federal funding agencies (CIHR, NSERC and SSHRC) and the Canadian General Standards Board (CGSB).

become a voluntarily-adopted policy for the conduct of ethical research by all REBs operating in Canada, though the voluntariness is somewhat apparent in that research institutions are eligible to receive federal funding from any of the three agencies only if the institutions adopt the TCPS2 (2014), which in turn requires not just their Tri-Council-funded research but all their human subject research to comply with the TCPS. Given how much research in Canada is federally funded, the TCPS2 (2014) effectively governs REBs and the ethics review processes in Canada, much as if it were legislated.

At the provincial and territorial levels, each government has enacted legislation pertinent to clinical research in its jurisdiction. For example, in Alberta, the Health Information Act (HIA) provides mechanisms to protect the privacy and confidentiality of personal health information. ${ }^{12}$ While it also describes the role of REBs in the disclosure of health information for research purposes, it does not prescribe binding rules for the operation of REBs in the province. ${ }^{12}$ Nevertheless, the HIA restricts the definition of REBs to those bodies designated by the regulations, meaning that only the provincial government has the power to enable REBs to operate in the province. In Alberta, at the time of this writing, there are three REBs - two at universities (University of Alberta, University of Calgary) and one as a provincial health organization. Alberta Innovates-Health Solutions (AIHS), established under the Alberta Research and Innovation Act and its regulations, is the provincial organization charged with the task of supporting health research and innovation in the province. ${ }^{13,14}$ As a result, AIHS saw the creation of the Health Research Ethics
Board of Alberta (HREBA), which conducts ethics reviews for researchers not affiliated with any academic or research institution in Alberta. By formal terms of reference, one specialist committee of the HREBA (viz., the HREBA-Cancer Committee) has exclusive jurisdiction over cancer research in the province.

\section{ReSEARCh Ethics OVERSight and HaRmonisation EFFORTS}

Research ethics boards, also known as institutional review boards (IRBs), are charged with the task of ensuring that investigators, sponsors and institutions comply with local, national and international regulations and guidelines that govern their conduct in clinical trials. REBs are typically-but not necessarily-associated with universities that conduct research involving human subjects. However, there are REBs that operate, under provincial legislation, without affiliation to academic institutions. Some are independent REBs operating as non-affiliated organizations; others, like the Ontario Cancer Research Ethics Board, are singlefocus REBs designed to undertake ethics reviews within specific fields. Although some countries, such as the United States and several members of the EU, have legislation in place that govern clinical trials and the role and procedures of REBs, there are no such detailed regulations in Canada. Instead, there is a framework of national and international policies and guidelines on research involving human subjects that does not, however, direct the function of REBs. Provinces have then taken it upon themselves to establish a legal framework for ethics reviews in their jurisdictions. The rather federally unregulated nature of REB 
operations in Canada offers an opportunity to ponder how effective the current federal and provincial approach is in providing protection for patients participating in clinical trials, as well as in assisting PIs wishing to conduct clinical trial research.

While the Food and Drug Regulations are the only federal legislation referring to REBs in Canada, it leaves a void in terms of regulating their daily operations and oversight. Granted, there are several federal initiatives that have led to the creation of panels, policies and standards, though they all lack the force of law. It could be argued that legislation alone will not result in an inter-provincial harmonised ethics review. However, the establishment of an entity with the authority to oversee REB operations while enforcing such policies and standards could promote the creation of a coordinated operational framework across Canada. Without such an initiative, it is left to the provinces to take on such responsibility. But, in keeping with evolved Canadian constitutional jurisprudence, health matters fall predominantly into the jurisdiction of the provinces rather than the federal domain, thereby making it a challenge to introduce federal regulation without the willing collaboration of all the provinces. Consequently, multi-centre clinical research in more than one province faces delays, as each centre follows procedures set by their province. It has been argued that this is due to federal REB regulation being seen as inappropriate intrusion on provincial jurisdiction, since matters considered in research ethics guidelines could fall within the regulation of the profession, which conventionally falls under provincial authority. ${ }^{15}$ Even so, several attempts have been made in the previous decade to bring about a pan-Canadian standard for research ethics.

In April 2010, HC and the Public Health Agency of Canada (PHAC) issued the Research Ethics Board's Operational Policy Framework for ethics review of research involving human subjects. ${ }^{16}$ This document was by no means conceived as a national framework for REB operations, though it could offer an insight into the guidelines followed by Health Canada's own REB, which is federally constituted. The Interagency Advisory Panel on Research Ethics (PRE) - created by Canada's three federal research agencies (the CIHR, NSERC and SSHRC) in 2001 - is an interdisciplinary body providing the agencies with independent reflection and advice on human research ethics, though it functions in an advisory capacity only. One of the PRE's mandates is to "participate in the ongoing national discussion regarding the development of an oversight system for the ethics review process." 17 In 2013, the Canadian General Standards Board, in cooperation with Health Canada, published the National Standard of Canada: Research Ethics Oversight of Biomedical Clinical Trials (CAN/CGSB-191.1-2013) as a way to provide clear REB operational procedures in order to avoid inconsistent interpretation of guidelines and policies. This voluntary standard is intended to improve the quality and reliability of ethics reviews as well as to impart consistency to REB operations across Canada. ${ }^{18}$ It incorporates essential aspects of REB operationssuch as governance, mandate and authority; composition and appointment; standard operating procedures; documents and recordkeeping; and quality management. ${ }^{18}$

In addition, the not-for-profit voluntary association called the Canadian Association of Research Ethics Boards (CAREB) is an informal but highly regarded national organization representing the interests of many, if not all, Canadian REBs, which aims to act as the voice of REBs in national policy discussions. It is somewhat akin in its aims to the United States organization called AAHRPP (the Association for the Accreditation of Human Research Protection Programs Inc.; pronounced "A-Harp"), which serves as a non-statutory but well-respected accreditation body for IRBs in the United States. It is not-for-profit and provides educational tools, templates and standards for IRBs. IRBs may apply to the AAHRPP to conduct a thorough site-and-document visit examination and, if satisfactory, then obtain accreditation by the AAHRPP. Such accreditation is taken into consideration by U.S. human health research funding bodies.

\section{Inter-Provincial Survey of Ethics RevieW HARMONISATION EFFORTS}

Despite all national efforts, in the absence of federal legislation, REBs are left to follow regulations stipulated by each provincial and territorial government. Provinces have been proactive in attempting to establish a framework for REB oversight and harmonisation in their jurisdictions. For instance, following constructive work among the provincial REBs, administrators and government officials toward provincial harmonisation of ethics review practices and procedures in order to eliminate duplication, introduce consistency and ensure sound ethical research in the province, Alberta produced a first-in-Canada reciprocity agreement among the Alberta REBs in 2010. In December of 2013, Alberta's Minister of Health signed a designation regulation reducing the number of HIA-designated boards in the province from the previous six to the current three REBs: the Health Research Ethics Board of Alberta (HREBA) at AIHS, the Conjoint Health Research Ethics Board (CHREB) at the University of Calgary and the Health Research Ethics Board (HREB) at the University of Alberta. ${ }^{19}$ According to the HIA Guidelines and Practices (chapter 8.15.1), in order to be eligible for and to maintain a designation under the Health Information Act, an REB must operate under the sponsorship of a research institution, professional body, regional health authority or other publicly funded body, ${ }^{20}$ thereby preventing the operation of independent REBs for clinical research within Alberta. Saskatchewan followed a similar harmonisation process, where only three provincially designated REBs can operate, with no room for independent REB reviews, as prescribed by their Health Information Protection Act. ${ }^{21}$ Manitoba created the Manitoba Provincial Health Ethics Network (MB-PHEN) in 2009 in collaboration with the Manitoba Regional Health Authorities. Its goal is "to advance ethics in healthcare in Manitoba," and it has developed a provincial health ethics strategy framework. ${ }^{22}$

British Columbia and Ontario are leading their own harmonisation initiatives. In 2007, British Columbia saw the need for a coordinated approach to ethics review in the province, resulting in the creation of the BC Ethics Harmonisation Initiative (BCEHI). Now in its phase II, the BCEHI is currently implementing and evaluating its pilot for harmonised ethics review models. Its goal is to improve the efficiency and effectiveness of the ethical review process, and to facilitate reciprocity between $\mathrm{BC}$ institutions for health research ethics review. ${ }^{23}$ Established in 2012, Clinical Trials Ontario (CTO) is Ontario's response to provincial standardization, acting as an independent not-for-profit organization supported by the Ontario Ministry of Research and Innovation. Its mandate is to improve Ontario's clinical trials environment, while supporting the highest ethical and quality standards. ${ }^{24} \mathrm{CTO}$ is 
leading the Streamlined Research Ethics Review System (SRERS), providing a single ethics review for multi-centre clinical trials, therefore reducing the paperwork and time taken to approve multi-centre research. As part of the SRERS, CTO is conducting the REB Qualification Program, intended to review REB operations, documentation, personnel and facilities, as indicated in existing regulations, standards and policies. Although it is not meant to serve as an all-encompassing provincial REB certification process, it is a first step toward REB oversight in the province.

In Québec, the Ministère de la Santé et des Services Sociaux du Québec (MSSS; Québec Ministry of Health and Social Services) has the task of overseeing institutional REBs, and it maintains a list of REBs by region and by affiliation type. ${ }^{25}$ Both independent and institutional REBs must abide by articles 20, 21, 22, 24 and 25 of the Civil Code of Québec with regard to children and vulnerable populations. Article 21 stipulates that research involving "a minor or a person of full age incapable of giving consent" must be approved and monitored by REBs designated by the MSSS, thereby preventing independent REBs from reviewing protocols involving such populations. ${ }^{26}$ This, however, gives nondesignated independent REBs the green light to operate in the province in any other kind of research.

Some of the eastern provinces have worked on bringing about a harmonised ethics review process. Newfoundland and Labrador, for example, established the Health Research Ethics Authority (HREA) by the Health Research Ethics Authority Act, which mandates that all health research in the province be approved by its Health Research Ethics Board. ${ }^{27}$ By doing so, the province has taken a centralised review approach by overseeing all health research involving human subjects. Similar to Ontario's approach, Clinical Trials New Brunswick was formed as the province's response to ethics review harmonisation. Managed by the two New Brunswick Regional Health Authorities, it aims to increase the efficiency of ethics review for multi-centre clinical trials. ${ }^{28}$

\section{Conclusions}

All things considered, it can be said that Canada is gradually moving toward provincial models of REB operations and oversight that share common elements. Harmonisation could prove beneficial to patients by encouraging multi-centre clinical trials to take place in more than one province, allowing patients to have access to more clinical studies across all provinces and territories, while ensuring patient safety through a standardised ethics review. At the same time, it allows PIs to have a clearer overview of the steps to follow when submitting for ethics review and carrying out clinical trial research. In summary, the procedure to follow by PIs conducting clinical research in Canada is primarily contingent on the province or territory of residence of the PI and the location of the research population. This is based on the fact that any research involving human subjects must go through ethics review, which is for the most part regulated by each provincial government. Another factor to consider is whether PIs are independent or affiliated with a research institution, such as a university. This could see PIs submitting for ethics review to a university-operated $\mathrm{REB}$, to a provincial REB or even to private independent REBs operating under provincial legislation. Unlike GCP, which must be followed as per the FDR, university-affiliated PIs are not legally bound to follow the TCPS2 (2014) by federal law, but they are so bound by their home institutions. Nevertheless, REBs have voluntarily adopted the TCPS2 (2014) as a national standard for the ethical conduct of research, thereby committing PIs to observe its guidelines.

\section{ACKNOWLEDGMENTS}

Josmar Alas received a stipend from the Master of Biomedical Technology summer internship program and from Dr. Aneal Khan from the University of Calgary Cumming School of Medicine.

\section{Disclosures}

Aneal Khan has the following disclosures. Actelion: consultant, consulting fees; Actelion: speaker, travel grant; Actelion: researcher, speaker's fees, research grants; Alexion: consultant, consulting fees, travel awards and research grants; Biomarin: consultant, consulting fees; Biomarin: researcher, travel grants and research grants; Cytonet LLC: consultant, research grants and consulting fees; Cytonet LLC: speaker, speaker fees and travel grant; Cytonet LLC: researcher, speaker fees and research grants; Genzyme: researcher, research grants; Genzyme: speaker, speaker's fees and travel grants; Genzyme: consultant/ICGG Board, consulting fees and travel costs; Horizon: researcher, travel grants and research grants; Horizon: consultant, consulting fees; Shire HGT: researcher, research grants; Shire HGT: speaker, speakers fees and travel awards.

Josmar Alas, Glenys Godlovitch, Connie Mohan and Shelly Jelinski hereby declare that they do not have anything to disclose.

\section{Statement of Authorship}

All persons who meet authorship criteria are listed as authors, and all authors certify that they have participated sufficiently in the work to take public responsibility for the content, including participation in the concept, design, analysis, writing or revision of the manuscript.

Conception and study design: JKA, AAK. Acquisition of data: JKA, CMM, SAJ. Analysis and/or interpretation of data: JKA, AAK. Drafting the manuscript: JKA, CMM, SAJ, GG, AAK. Revising the manuscript critically for important intellectual content: JKA, CMM, SAJ, GG, AAK. Approval of the version of the manuscript to be published: JKA, CMM, SAJ, GG, AAK.

\section{REFERENCES}

1. Butler D, Callaway E. Scientists in the dark after French clinical trial proves fatal. Nature. 2016;529:263-4; Available at: http://www. nature.com/news/scientists-in-the-dark-after-french-clinical-trialproves-fatal-1.19189.

2. Enserink M. France tightens rules in wake of fatal clinical trial. Science. Epub ahead of print May 23, 2016. Available at: http://www.sciencemag.org/news/2016/05/france-tightens-ruleswake-fatal-clinical-trial.

3. Health Canada. Clinical Trial Regulations. Ottawa: Health Canada. Available at: http://www.hc-sc.gc.ca/sr-sr/advice-avis/reb-cer/pol/ clini-reg-eng.php.

4. Food and Drugs Act (Canada), RSC. 1985, Chapter F-27, and its corresponding regulations for clinical trials. Food and Drug Regulations. Consolidated Regulations of Canada; 1985. Available at: http://laws-lois.justice.gc.ca/PDF/C.R.C.,_c._870.pdf.

5. Protection of Human Subjects, 45 C.F.R. 46; 2009. Available at: https://www.hhs.gov/ohrp/regulations-and-policy/regulations/ 45-cfr-46/.

6. European Commission. Directive 2001/20/EC of the European Parliament and of the Council of 4 April 2001 on the Approximation of the 
Laws, Regulations and Administrative Provisions of the Member States Relating to the Implementation of Good Clinical Practice in the Conduct of Clinical Trials on Medicinal Products for Human Use. Brussels: European Commission; 2001. Available at: http://ec.europa. eu/health/files/eudralex/vol-1/dir_2001_20/dir_2001_20_en.pdf.

7. Health Canada. ICH Guidance E6: Good Clinical Practice. Consolidated Guideline. Ottawa: Health Canada; 1997. Available at: http://www.hc-sc.gc.ca/dhp-mps/prodpharma/applic-demande/ guide-ld/ich/efficac/e6-eng.php.

8. International Council for Harmonisation of Technical Requirements for Pharmaceuticals for Human Use. ICH Harmonised Tripartite Guidelines: Guideline for Good Clinical Practice E6(R1). Geneva: The Council; 1996. Available at: http://www.ich.org/fileadmin/ Public_Web_Site/ICH_Products/Guidelines/Efficacy/E6/E6_R1_ Guideline.pdf.

9. Canadian Institutes of Health Research, Natural Sciences and Engineering Research Council of Canada, Social Sciences and Humanities Research Council of Canada. Tri-Council Policy Statement: Ethical Conduct for Research Involving Humans, TCPS2 2014. Ottawa: Secretariat on Responsible Conduct of Research; 2014. Available at: http://www.pre.ethics.gc.ca/eng/ policy-politique/initiatives/tcps2-eptc2/Default/.

10. McDonald M. From code to policy statement: Creating Canadian policy for ethical research involving humans. Health Law Review. 2009;17(1-2): 12-25.

11. Gauthier MC, Hoddinott S, Nestruck C, Valiquette MF. Harmonisation of the Tri-Council Policy Statement: Ethical Conduct for Research Involving Humans (TCPS) and ICH-Good Clinical Practice: Conflict or Clarification? Ottawa: Interagency Advisory Panel and Secretariat on Research Ethics; 2007. Available at: http://www.pre.ethics.gc.ca/policy-politique/initiatives/docs/FINAL_ TCPS-GCP_Harmonization_Nov_2007___EN.pdf.

12. Health Information Act. Revised Statuses of Alberta, Chapter H-5; 2010. Available at: http://www.qp.alberta.ca/documents/Acts/H05.pdf.

13. Alberta Research and Innovation Act. Statuses of Alberta, Chapter A-31.7; 2009. Available at: http://www.qp.alberta.ca/documents/ Acts/A31P7.pdf.

14. Alberta Research and Innovation Regulation. Alberta Regulation 203; 2009. Available at: http://www.qp.alberta.ca/documents/ Regs/2009_203.pdf.

15. Lemmens T. Federal regulation of REB review of clinical trials: a modest but easy step towards an accountable REB review structure in Canada. Health Law Review. 2005;13(2-3):39-50.

16. Health Canada. Research Ethics Board's Operational Policy Framework: Ethics Review of Research involving Human Subjects.
Ottawa: Health Canada; 2010. Available at: http://healthycanadians. gc.ca/publications/science-research-sciences-recherches/ethicsresearch-human-subjects-framework-cadre-ethique-rechercheetres-humains/index-eng.php\#a1.

17. The Interagency Advisory Panel on Research Ethics. Ottawa: The Panel; 2016. Available at: http://www.pre.ethics.gc.ca/eng/panelgroup/tor-cdr/.

18. Canadian General Standards Board. Research Ethics Oversight of Biomedical Clinical Trials. Ottawa: Standards Council of Canada; 2013. Available at: http://www.southlakeregional.org/doc.aspx? $\mathrm{id}=877$.

19. Alberta Innovates Health Solutions. Update on Health Research Ethics Harmonization. Edmonton: Alberta Innovates Health Solutions; 2016. Available at: http://www.aihealthsolutions.ca/ news-and-events/media-centre/hia-designated-rebs-reducedto-three-and-full-reciprocity-on-its-way/.

20. Government of Alberta. Health Information Act: Guidelines and Practices Manual. Edmonton: Government of Alberta; 2011. Available at: http://www.health.alberta.ca/documents/HIAGuidelines-Practices-Manual.pdf.

21. The Health Information Protection Act. Statuses of Saskatchewan; 1999; Chapter H-0.021. Available at: http://www.publications. gov.sk.ca/details.cfm? $\mathrm{p}=4523$.

22. Manitoba Provincial Health Ethics Network. About Us. Winnipeg: The Network; 2009-2016. Available at: http://www.mb-phen.ca/ about.html.

23. BC Ethics Harmonization Initiative. About BCEHI. Vancouver: Michael Smith Foundation for Health Research; 2016. Available at: https://bcethics.ca/about/.

24. Clinical Trials Ontario. About Clinical Trials Ontario. Toronto: Clinical Trials Ontario; 2014. Available at: http://www.ctontario. ca/about/.

25. Santé et Services Sociaux Québec. Répertoire des Établissements du RSSS, des CER et des CEC. Quebec: Santé et Services Sociaux Québec; 2016. Available at: http://ethique.msss.gouv.qc.ca/lethiquede-la-recherche/repertoire-des-etablissements-du-rsss-des-cer-et-descec.html?tx_repertoirecer_pi $1 \% 5 \mathrm{~B}$ formAction $\% 5 \mathrm{D}=$ tableau.

26. Civil Code of Quebec. Chapter CCQ; 1991. Available at: http:// legisquebec.gouv.qc.ca/en/showdoc/cs/CCQ-1991.

27. Health Research Ethics Authority of Newfoundland and Labrador. About Us. St John's, NL: The Authority; 2016. Available at: http://www.hrea.ca/About-Us.aspx.

28. New Brunswick Health Research Foundation. Clinical Trials New Brunswick. Fredericton, NB: The Foundation; 2009-2015. Available at: http://www.nbhrf.com/clinical-trials-new-brunswick. 